\title{
Research on Project Management system of Large Complex Construction Projects Based on cloudDB
}

\author{
Jian-jun HAN ${ }^{1,2 a}$,Wen-xia LI ${ }^{1}$, CHENG Yu ${ }^{2, b}$ \\ ${ }^{1}$ College of Civil Engineering, Zhengzhou University of Industry Technology,Xinzheng, Henan china \\ ${ }^{2}$ School of Civil Engineering and Architecture, Henan University of Technology, Zhengzhou, Henan \\ china \\ ahan_7485@163.coml, bpch-y@163.com
}

Keywords: cloud database, large, complex projects, management system

Abstract: This paper begins with analyzing the characteristics of large and complex project management systems and creatively puts forward constructing a large, complex project management system by usingcloud databases. Afterwards, the structure chart and functional diagram of large and complex project management systems based oncloud databases is presented, Last but not least, important functions and implementation method of key technologies are advocated in this paper.

\section{Introduction}

With the rapid expansion of China's economic scale, high-speed development of infrastructure and improvements and perfection of construction project management systems nationwide, large and complex project construction is well under way without signs of slackening ${ }^{[1]}$. Large, complex projects are typically characterized by varied construction contents, massive investment and high quality standards, etc. How to achieve effective control of the quality, cost and schedule of large and complex projects, share engineering information, and demonstrate project progress in a real-time, visualized and interactive way have become the requirements for controlling and managing large and complex projects. On the other hand, with the growing development and popularity of computer and network technology, the construction industry has enabled to capitalize on computer and network technology for information control and management. In terms oflarge and complex projects, using cloud databasesto realize interactive control and management canhelpeach project participant andrelated departmentto retrieve, inquire, communicate and integratethe engineering progresses, and alsoeffectively transfer and mine data information, thuslargely improving the management level of large and complex projects.

\section{Characteristics of large and complex projects}

In addition to the features of one-off engineering, huge amounts of investment, long construction period and extensive environmental impacts, a large and complex projectstill has the following characteristics in the global network system:

(1) Project systematicness. Systematicness of large and complex projects isexhibited in space and timesystematicness. In using any practical large and complex projects, all functional 
subsystems must be completed. This particularly requires project management to comprehensively take intoaccountthe construction and connection of multiple subsystems, including all sub-items, auxiliary facilities, infrastructure and external support, while the functions of these subsystems has also covered the completion of multiple tasks, encompassing design, construction, equipment manufacturing, transportation, installation, debugging and integration.

(2) Spatial separation of production supply and use. Large and complex projects are generally carried out in economically active cities, possibly the bustling areas there. As for the construction site, environmental adaptability should be considered on the one hand; on the other hand,construction machinery, materials, equipment, personnel access and departure should be taken into account. These require separating the equipment and material production supply from the using space during the project implementation course. Further, adhere to lean production, ensuresmooth and orderly production, transportation, transport outside the city, andentry anddeparture, and resist certain risk factors.

(3) Global distribution of production and supply. The implementation of large and complex projects also often reflects a country's overall manufacturing capability.In the international network today, many components are produceduniversally. How to easily monitor and manage the production and transportation of necessary components on a global scale, as well as considering the risk factors that may exist, should be a priorityforthe project management system.

(4) Arrangement and output diversity of massive data. Given the long implementation cycle, enormous participants involved and diversification of regions involved, large and complex projects should be arranged, organized and output. At different departments and different time, data information is diverse, which has become a new trend of data processing under the new situation.

As thus, comparingwith general industrial and even general construction projects, large and complex projects place greater emphasis on process control. How to implementall-round and whole process management of large and complex projects in a systematic, networked, intelligent and interactive way, and improve the visualization and operability of the management system have been the current target and direction of large and complex project management systems.

\section{Large and complex project management systems based on cloud databases}

A cloud database refers to a database that is optimized or deployed to a virtual computing environment. The development of a database can be simply divided into three stages: standardizeddata centralization, resource-oriented data virtualization and service-oriented cloud data. In essence, a cloud database is to change the single computing center model, thus coordinating and configuring global data resources more flexibly, highefficiently and economically. Among them, centralization is the premise, networking is the method, and a cloud database is the target and a higher level of data information. Nowadays, with the development of information technology, a cloud databasemoves closer to us and gradually enters into the testing phase and partially achieves practical applications ${ }^{[2]}$.

\section{Construction of large and complex project management systems based on cloud databases Structural design of large, complex project management systems based on cloud databases}

The structural design of the project management system is the model to realize system functions, information input and output, and external interface relations. Large, complex project management systems based on cloud databasesuses the Web structure and is directly based on the Internet platform. This will undoubtedly adapt to the actual situation that all participants of large 
and complex projects are widely distributed and geographically dispersed.

The system adopts the constitutive system consisting of the Java language and multi-layer components. In order to improve system security and reliability, the system provides $\mathrm{D} / \mathrm{B}$ three-layered services--Web services, business application services and data management services--for data information. Based on the Web platform, the system development consistently implements a unified mobile terminal and browser's access to the system.

Some system transactions may be completed on a mobile terminal or a fixed terminal;keytransactions are completed on the cloud database, which submits complex data to the server. In this way, it can not only reasonably allocateand use resources, but also ensure the flexibility of the client. Its physical structure is shown in Figure 1.

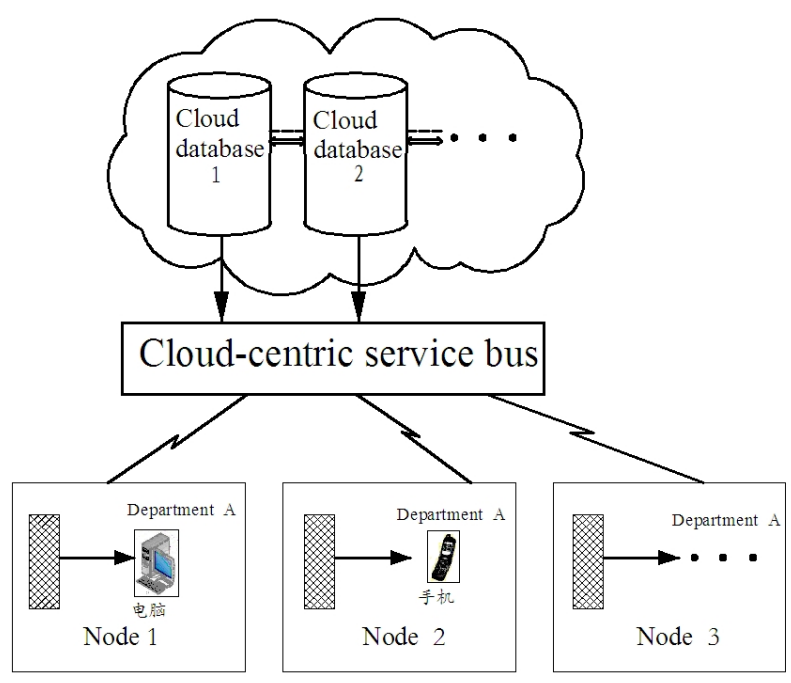

Figure 1.Schematic diagram of the system physical structure

To ensure the security of the system and data information, a variety of information security technologies are employed, such as digital signatures, cryptographic algorithms and trusted logging.

\section{Functional design of large and complex project management systems based on cloud databases}

As aforementioned, considering the actual needs of large and complex project management systems based on cloud databasesand the current development of communications and management techniques, a schematic diagram regarding the system function structure is proposed, as shown in Figure 2.

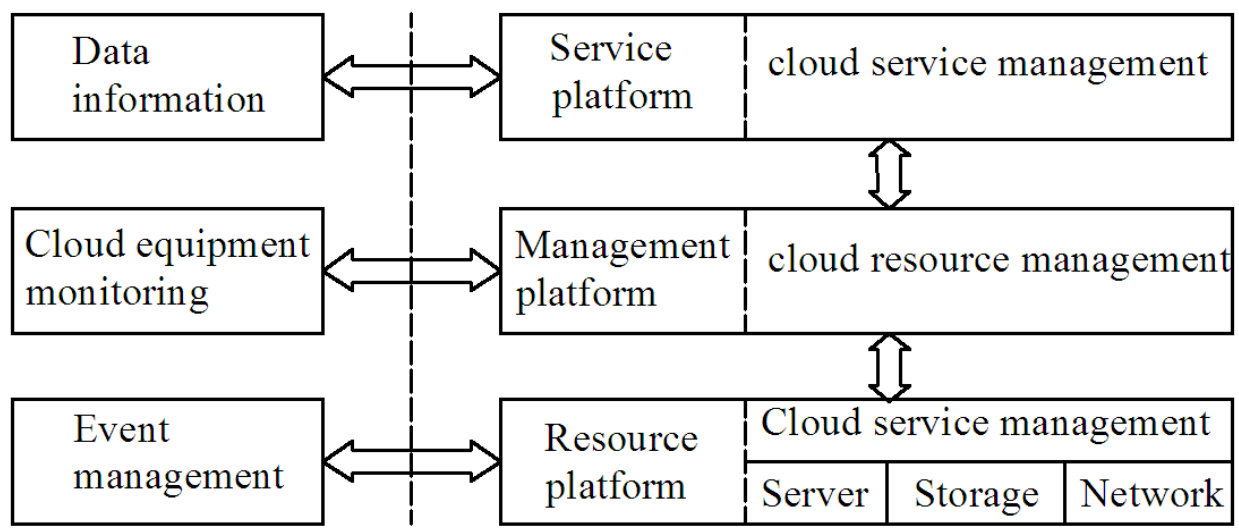

Figure 2.Schematic diagram regarding the system function structure 
In this paper, some important functions are briefly introduced.

(1) Data storage and management functions. Massive data are stored by means of cloud storage. It should be noted that due to a large number of units and personnel involved in large and complex projects, different levels of administrationauthority proposes different requirements for data needs, which not only set permissions in interface operations and flow processing, but also requires data tagging management fordata collection and input, so as to facilitate data transmission and calling, as shown in Figure 3 (some portions of this figure).

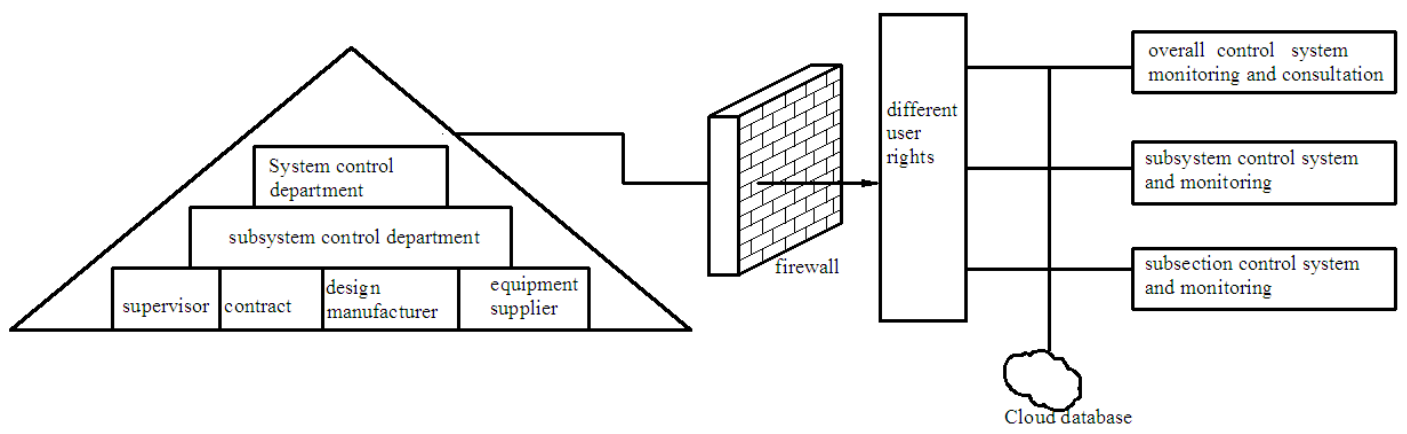

Figure 3 Hierarchical control diagram

(2) Data management and analysis. With the advent of the big data era, the cloud database is a powerful tool for efficient data analysis.Using the cloud database can easily achievemanagement and analysis of vast amounts of information and ensure data securitythrough the highly reliable architecture.

(3) Project daily management and early warning functions. The project daily management system is comprised of quality management subsystem, schedule management subsystem, funds management subsystem and contract management subsystem. When the system is set, project management and control planning are fully considered to carry outsystem management plans and control plans andmutual coordination forintercoordination. During system development, set early warning parameters and corresponding plans as per the project plan and practical conditions, and perform warning as per grading and authority. If the project plan and earlywarning parameters should beadjusted during the project implementation process, there should be a higher level of authority.

(4) Remote data acquisition and physical positioning functions. Utilize remote radio frequency identification devices (RFID), infrared sensors, global positioning systems, laser scanners, gas sensors and other information sensing devices, in accordance with the agreed protocol, extend and expand the terminal to the production and testing equipment for information exchanges and communications, to achieve informationization, intelligent remote recognition, positioning, tracking, monitoring and management of globalizedand remote production equipment. Global production data, experimental data and test data can all realize remote collection and are presented in a visual way.

(5) Remote diagnosis and decision support functions. Use thediagnosis reasoning of a fault tree, diagnostic reasoning ofequipment monitoring alarm, and reasoning of condition monitoring information combined with online expert diagnosis and teleconferencecanattain to remote diagnosis and follow-up schemes based on the diagnostic results. 


\section{Advantages and Characteristics of large and complex project management systems based oncloud databases}

(1)Large and complex project management systems can not only safely and efficiently store and manage data; more importantly, they can dig and analyze data under the premise of low costs, high efficiency and stronglyreliable security, and present information in a diversified way.

(2) Large and complex project management systems can easily construct theInternet of things, thus quickly and conveniently achieving globalized and lean production and transportation, and largely avoiding thefalse behavior by manufacturers, suppliers or laboratories.

(3) Provide aninformation exchange and sharing platform for manyparticipants in large complex projects. Each participant can acquire necessary information interactively andarrange production and constructionindependently through system visualization, with no need to gaininformation relying on traditional and lagged monthly and weekly journals.

(4)The system has good warning and early warning functions, as well ascorresponding pre-arranged plans.Besides, early warningsandpre-arranged planning can be transmitted in a timely manner and targeted at people, so thatearly warnings and pre-arranged plans canhave a definite object in view and be easy to operate.

(5) The system can easily update and organize information, supported by acceptance and assessment.

(6) Thesystem is conductive for information disclosure, which provides a good display platform for the project.

\section{Conclusion}

There isno doubt that applying modern information technology canimprove the management techniques and means of large, complex projects, which is beneficial to improve the efficiency and effectiveness of project management.Specially,process information management system in large and complex projects based on cloud databases can guarantee the project process is compact, normalized,methodic, and can avoid disorder and blindness. Moreover, it can help ensure the successful completion of large and complex projects on schedule, improve the efficiency and benefits of projects and give play to returns on investment. Although the information technology, networking and cloud platform arestill in infancy in domestic engineering construction, it is believed that with increasingly awareness of the high efficiency and convenience brought about by informatization, networking and the cloud platform, as well as a greater number of practical cases, cloud databases and other information technologieswill be comprehensively promoted for project management and control.

\section{References:}

[1] The State Council. Opinions of the State Council on Strengthening Construction of Infrastructure[N], 2013.

[2]IrtishadAhmad.Managing, processing and communication information[J]. Journal of Management in Engineering, 2013,24(3):165-173.

[3]Cravford B., Soto R. A new approach to solve the software project scheduling problem based on Max-Min ant system[J]. Intelligent systems and computing,2014,285(6):41-51

[4]Liu Yunlong,ChenJIaner,WangJiaxin. On counting3-D matching of size[J].Aogroithmica,2009,54(10):349-359 
[5]Hiremath N., Sahu S. Multi objective outbound logistics network design for a manufacturing supply chain[J]. Journal of intelligent manufacturing, 2013,24(1):1071-1084 